
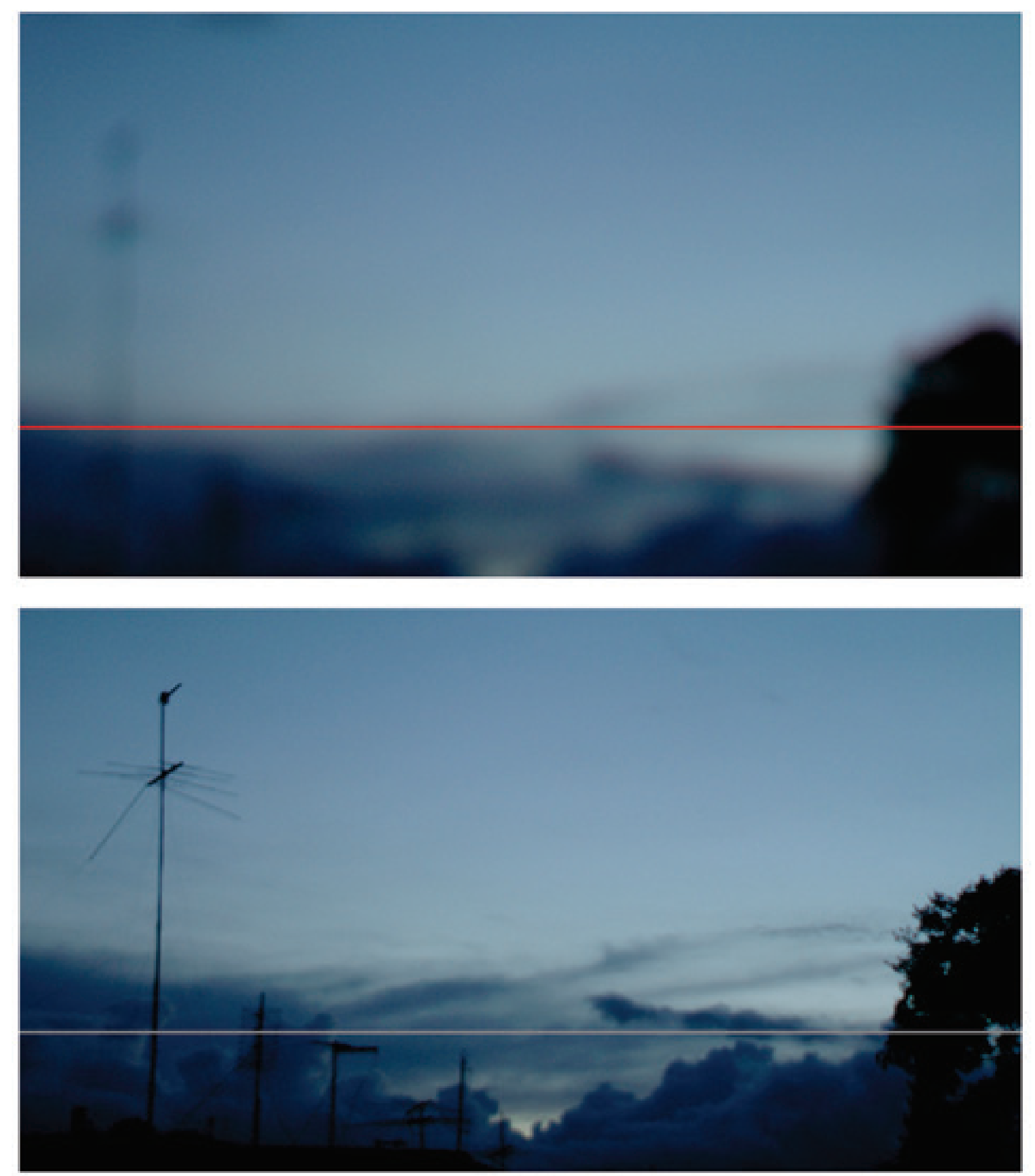


\title{
Planejamento territorial do turismo na Região Metropolitana de Curitiba
}

\section{Territorial Tourism Planning in Curitiba Metropolitan Region}

\author{
Margarete Araujo Teles ${ }^{1}$
}




\title{
Resumo
}

Este artigo apresenta uma análise do Planejamento Territorial do Turismo na Região Metropolitana de Curitiba (RMC), com objetivo de avaliar a inserção do turismo nas políticas públicas dos municípios da região por meio de instrumentos de planejamento e entrevistas com os gestores públicos. A metodologia de trabalho caracteriza-se por uma abordagem analítica e empírica. Fundamenta-se em reflexões sobre o planejamento turístico e instrumentos de ordenação territorial. Nos procedimentos operacionais foram aplicadas as técnicas de pesquisa documental e pesquisa de campo. Os resultados da pesquisa documental e empírica apontaram que embora existam orientações para uso de instrumentos de planejamento para o turismo municipal e regional, observa-se que os atores responsáveis pelo planejamento no âmbito metropolitano ficam sujeitos às decisões políticas para implementar suas ações e instrumentos de planejamento. Este estudo evidencia a necessária organização de políticas públicas no território, com vista a promover o turismo de forma sustentável.

Palavras-chave: Turismo. Planejamento. Políticas Públicas. Plano diretor.

\begin{abstract}
This article presents an analysis of Territorial Tourism Planning in Curitiba Metropolitan Region (CMR), to evaluate the inclusion of tourism into the public policy of the municipalities of the region through planning instruments and interviews with public managers. The work methodology is characterized by both analytical and empirical approach. It is based on reflections on tourism planning and instruments of territorial ordination. As the operating procedures were applied the techniques of documentary and field research. The results of the documental and the empirical researches pointed out that although there are guidelines for the use of planning tools for local and regional tourism, it is observed that the responsible actors for planning at the metropolitan level are subjected to the political decisions to implement its policies and planning instruments. This study highlights the necessary public policy organization in the territory, aiming to promote tourism in a sustainable manner.
\end{abstract}

Keywords: Tourism. Planning. Public policy. Master plan.

\section{Introdução}

O turismo tem sido considerado um setor estratégico para regiões e países que buscam o desenvolvimento econômico, tendo em vista seu expressivo crescimento nas últimas décadas em termos de fluxos e de participação na economia mundial. $\mathrm{O}$ desempenho do setor está relacionado a fatores como comportamento da renda e sua distribuição, bem como à disponibilidade de tempo livre e outras facilidades propicia- 
das pelo progresso tecnológico, rapidez nas comunicações e evolução dos transportes.

Com isso, o turismo tem assumido um papel importante nos discursos governamentais como gerador de renda, emprego e divisas. O efeito disso são as propostas de planejamento para essa atividade que vêm sendo incorporadas às políticas públicas de diversos países. No caso do Brasil o processo não é diferente. As políticas públicas do turismo vêm se delineando nessa perspectiva, especialmente a partir da década de 1990, quando são delineadasdiretrizes mais concretas para o desenvolvimento do turismo por meio da Política Nacional de Turismo, Planos Nacionais de Turismo e institucionalização do Ministério do Turismo em 2003.

A Região Metropolitana de Curitiba (RMC) faz parte do cenário turístico do Estado do Paraná e do Brasil. Em decorrência disto, o turismo vem sendo incorporado desde 1996, no planejamento da RMC, cujos objetivos são desenvolver o turismo rural, o agroturismo, o ecoturismo e o lazer.

Assim, o objetivo deste estudo foi avaliar a inserção do turismo nas políticas públicas dos municípios da Região Metropolitana de Curitiba, por meio de instrumentos de planejamento e entrevistas com os gestores públicos e privados, com a finalidade de identificar se o setor faz parte das estratégias do planejamento regional.

A metodologia de trabalho adotada baseia-se no uso da abordagem analítica e pesquisa de campo. A abordagem analítica consistiu na análise documental dos planos diretores municipais. Desse modo, utilizaram-se 17 planos diretores dos municípios da RMC para identificar como o setor de turismo estava inserido nas políticas públicas dos municípios, já que este instrumento de planejamento é o norteador do ordenamento do território, e a partir de 2001 tornou-se obrigatório no Brasil para os municípios com mais de 20.000 habitantes.

Como critérios para identificar como o setor de turismo estava inserido nos planos diretores, foram selecionados conteúdos que se relacionavam especificamente com a temática.

Quanto à pequisa de campo, entrevistas estruturadas foram aplicadas aos gestores municipais de turismo, com objetivo de verificar a existência de planos, projetos, fundos municipais, conselhos municipais e confirmação dos planos diretores. A análise de dados e a discussão dos resultados permitem tecer algumas considerações sobre a utilização dos instrumentos de planejamento territorial do turismo na Região Metropolitana de Curitiba.

Para dar conta da análise proposta estrutura-se o artigo com aporte teórico sobre planejamento do turismo, contextualização da Região Metropolitana de Curitiba, 
análise e discussão dos resultados sobre o turismo na RMC e, por fim, as considerações finais.

\section{Planejamento do Turismo}

O planejamento do turismo é visto como uma ferramenta metodológica importante na condução das políticas públicas. Assim, organizações como a Organização Mundial do Turismo e World Travel \& Council e governos em diferentes escalas têm reconhecido a necessidade dessa ferramenta para o desenvolvimento do turismo em regiões. Nessa perspectiva, diversos estudiosos também destacam o papel do planejamento do turismo (RODRIGUES, 1997; BENI, 2001, 2003, 2006; CRUZ, 2006; SILVEIRA, 2002; COOPER, FLETCHER e WANHILL, 2007, e outros).

A importância que se deve dar ao planejamento do turismo tem por pressuposto que esta atividade vem crescendo nas mais diversas regiões do mundo, muitas vezes de forma desorganizada. Com isso, são necessárias ações de planejamento que promovam a elaboração de políticas públicas de turismo com vistas a integrar e articular a atividade a outros setores para que ela possa se desenvolver de forma equilibrada no território.

Diante disto, numa concepção global, Cooper, Fletcher e Wanhill (2007, p. 317) afirmam que

o planejamento do turismo nacional abrange os planos de desenvolvimento do turismo para um país como um todo, mas muitas vezes inclui objetivos específicos para regiões subnacionais ou tipos de áreas dentro das fronteiras nacionais.

Assim, o planejamento turístico deve ser proposto tanto para locais cujos potenciais de turismo ainda não foram desenvolvidos como para aqueles que já se encontram no processo de desenvolvimento do turismo, uma vez que o planejamento, além de propor ações futuras, é igualmente um processo contínuo de adaptação e controle das ações.

Além disto, a exigência do planejamento turístico governamental e da intervenção do Estado no processo de desenvolvimento do turismo decorre da necessidade de oferecimento de respostas aos problemas inerentes a esse desenvolvimento e, principalmente, de prevenção contra os efeitos indesejados que o crescimento da atividade pode provocar, em especial nos âmbitos local e regional (SILVEIRA, 2002).

Em relação ao planejamento regional, Cruz afirma que

requer a abdicação, por parte dos poderes públicos e municipais, de parte de seus projetos individuais em prol de um projeto coletivo [...], pode significar para muitas municipalidades, a única possibili- 
dade de inserção no seleto rol de lugares que conseguiram fazer do turismo um instrumento de seu desenvolvimento social e econômico. (CRUZ, 2006, p. 343)

O planejamento turístico, além de abranger o poder público, deve estar no bojo das organizações privadas, uma vez que estes dois setores devem estar integrados para desenvolver o turismo na localidade.

Dadas as múltiplas relações que tem o turismo com outros setores, uma ferramenta para sua organização é a Política Nacional do Turismo, desde que compreenda as políticas setoriais, visto que o turismo depende de outras infraestruturas como transporte, elemento essencial para o deslocamento dos turistas, setores da saúde, saneamento básico, educação e toda a infraestrutura específica do turismo (AUTOR, 2011).

Deste modo, o planejamento territorial do turismo deve fazer parte das políticas públicas em todas as escalas, local e regional, e outros setores devem ser envolvidos na perspectiva de reconhecer o turismo como fenômeno que gera benefícios econômicos e sociais, proporcionando impactos na economia local e regional. Além disso, deve-se planejar o turismo para que não ocorram impactos negativos da atividade no território.

É importante também salientar que o turismo se dá num espaço físico, e o planejamento deve cuidar, nos seus pressupostos básicos, do uso do solo e dos recursos ambientais, dos quais o turismo depende em grande parte para existir.

Neste sentido, o Plano Diretor como instrumento básico de um processo de planejamento municipal para implementação da política urbana deve orientar todas as ações concretas de intervenção sobre o território (BRASIL, 2002). Assim, o turismo, como atividade que se produz no espaço urbano, deve fazer parte desta política. Isto está previsto na Constituição Federal, Capítulo I, Art. 180 (BRASIL,1988), que afirma: "a União, os Estados, o Distrito Federal e os municípios promoverão e incentivarão o turismo como fator de desenvolvimento social e econômico".

Ainda no âmbito da legislação, o Estatuto da Cidade, Lei n.o 10.257, Capítulo III, Art. 41, também prevê, conforme incisos abaixo, no plano diretor a inserção do turismo no ordenamento territorial dos municípios

I - com mais de vinte mil habitantes;

II - integrantes de regiões metropolitanas e aglomerações urbanas;

III - onde o Poder Público municipal pretenda utilizar os instrumentos previstos no 4. ${ }^{\circ}$ do art.182 da Constituição Federal: 
IV - integrantes de áreas de especial interesse turístico;

$V$ - inseridos na área de influência de empreendimentos ou atividades com significativo impacto ambiental regional ou nacional (BRASIL, 2008, p. 27).

O Plano Diretor é um instrumento importante para os planejadores de turismo e outros profissionais, pois pode fornecer a base para o planejamento estratégico do setor, uma vez que apresenta um diagnóstico completo do município, com vários dados que podem auxiliar nos inventários turísticos. Ou seja, aquele município que precisa ter informações sobre sua potencialidade turística deve utilizar o Plano como ferramenta de pesquisa, numa primeira etapa, já que muitos dados de infraestrutura e potencialidades de uso e ocupação do solo e outros elementos fazem parte do diagnóstico municipal.

É por meio da perspectiva de um plano diretor que estão as referências exequíveis dos planos de governo. Se o município dispõe da lei de uso e ocupação do solo, deve rever de que forma ela contempla, e se contempla, questões como: a do turismo e da proteção da paisagem; a da autonomia dada ao município quanto à eleição das zonas de urbanização; que tipo de zoneamento e vizinhanças convém em cada zona; que taxa de ocupação dos lotes é desejável; quais são as orientações específicas do turismo e da preservação ambiental. Além dessas questões, deve haver uma preocupação com o diferencial do local onde irá se desenvolver a atividade turística (YÁZIGI, 1999).

Além do Plano Diretor, o município deve ter o órgão oficial de turismo, criado por Lei Municipal, responsável por implementar as políticas municipais de turismo, a gestão municipal do turismo que deve contar com o conselho municipal de turismo, fundo municipal de turismo, incentivos ao turismo, formalização das empresas de turismo, ferramentas necessárias às políticas públicas do setor (SETU, 2005).

No Brasil, o Ministério do Turismo (MTUR) orienta para que os municípios possuam seus instrumentos de gestão municipal, e também o Plano Municipal de Desenvolvimento Sustentável do Turismo ( BRASIL, 2007).

\section{Região Metropolitana de Curitiba e configuração espacial}

A Região Metropolitana de Curitiba, no Estado do Paraná, Brasil, conta com uma área territorial de $16.627,209 \mathrm{~km}^{2}$, população censitária de 3.223 .836 (IBGE, 2010), e é composta por 29 municípios: Campo Magro, Almirante Tamandaré, Pinhais, Piraquara, São José dos Pinhais, Bocaiúva do Sul, Lapa, Contenda, Quitandinha, Agudos do Sul, Tijucas do Sul, Mandirituba, Fazenda Rio Grande, Quatro Barras, Campina Grande do Sul, Colombo, Itaperuçu, Adrianópolis, Cerro Azul, Doutor Ulysses, Piên, 
Rio Negro, Rio Branco do Sul, Tunas do Paraná, Araucária, Balsa Nova, Campo Largo, Campo do Tenente e Curitiba (Figura 1).

FIGURA 1: LOCALIZAÇÃO DA REGIÃO METROPOLITANA DE CURITIBA

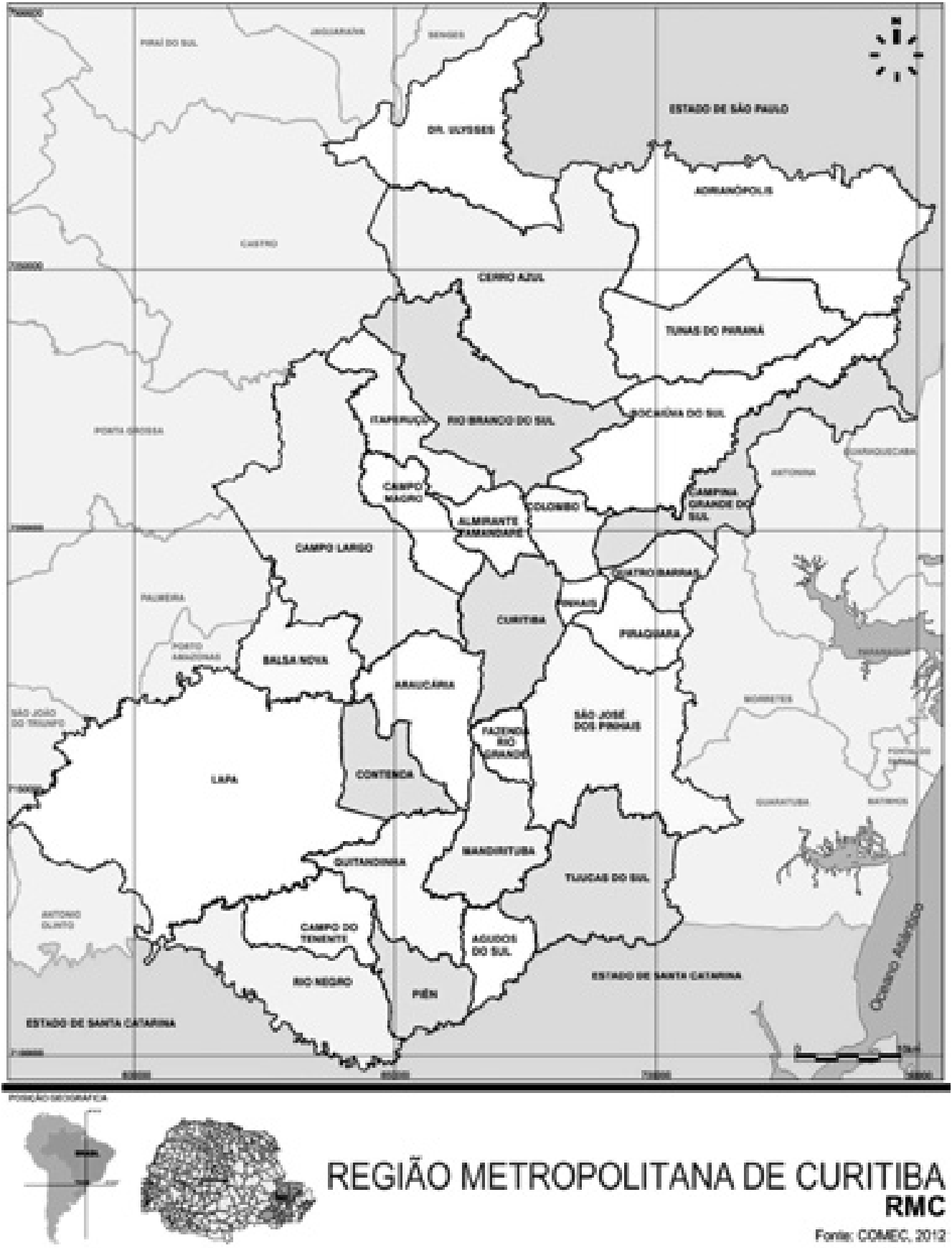

FONTE: Base cartográfica COMEC (2012). 
Quanto ao acesso rodoviário, a RMC comporta os principais corredores para acesso ao litoral (BR 277 e Estrada da Graciosa) a partir de Curitiba, a rodovia BR 277, no sentido Foz do Iguaçu (principal destino turístico do Estado) e as rodovias BR 376 (Norte) e PR 151 (Norte Pioneiro).

Os municípios da Região Metropolitana de Curitiba se destacam dentre as maiores economias do Estado. Em razão do dinamismo da indústria e dos serviços, Curitiba, Araucária e São José dos Pinhais são os municípios mais representativos no PIB do Paraná (IPARDES, 2011).

Nas atividades econômicas da RMC, segundo dados do IPARDES (2011), pelo valor adicionado fiscal (VAF), dados estes coletados na Secretaria da Fazenda do Estado do Paraná em primeiro lugar tem-se a indústria e em segundo lugar, comércio e serviços.

Em um processo mais recente, nas áreas rurais dos municípios da aglomeração metropolitana de Curitiba, vem se consolidando uma estrutura de serviços vinculada ao espaço rural, o que tem sido caracterizado como novas funções do rural (hotelaria, restaurantes, lazer).

Neste cenário, a ocupação do solo metropolitano pela população e as diversas atividades econômicas têm ocasionado conflitos ambientais, sociais e de infraestrutura, conforme diagnósticos da Coordenação da Região Metropolitana de Curitiba (2006) IPARDES (2004).

Em contraposição àqueles municípios com condição socioeconômica mais favorável, alguns municípios de pequeno porte, localizados ao norte da região, possuem fortes restrições ao desenvolvimento agrícola, mas com importante participação de população rural, e, distantes do polo metropolitano, apresentam as situações mais precárias "nas dimensões sociais de educação, saúde, habitação, infra-estrutura urbana e pobreza, e valores do IDH-M entre os mais baixos do Estado" (IPARDES, 2004 , p. 31). Além disto, existe a ocorrência do isolamento no que concerne às comunicações viárias.

\section{Turismo na Região Metropolitana de Curitiba}

A partir do conjunto de técnicas de pesquisa utilizadas neste estudo, dos dados coletados por meio da pesquisa bibliográfica documental e da observação direta intensiva, com a visão dos gestores públicos municipais e estadual, foi possível obter um quadro da situação da RMC no que tange às políticas e ações de turismo. 


\subsection{Institucionalização do Turismo nos planos diretores da Região Metropolitana de Curitiba}

O processo de planejamento do turismo na RMC se deu a partir de 1996 por meio da COMEC, com apoio da EMATER, diante da necessidade de se criar alternativas de renda e emprego, já que a região tinha (e tem) restrições para uso e ocupação do solo. Visava o projeto, principalmente, proteger os mananciais, comprometidos por meio de atividades agrícolas com uso de agrotóxicos, especulação imobiliária, além de atividades industriais.

A característica principal da oferta turística organizada sob a forma de roteiros na $\mathrm{RMC}$ estava relacionada às temáticas das etnias colonizadoras da região, dos produtos locais e dos recursos naturais presentes. Nesse contexto, houve uma preocupação em exaltar características existentes que pudessem identificar e diferenciar os roteiros uns dos outros, destacando vocações locais (SILVEIRA, 2011).

A análise realizada na Região Metropolitana de Curitiba identificou que a maioria dos planos foi aprovada entre 2001 e 2009. Constatou-se que, dos 17 planos diretores pesquisados, 10 (Contenda, Curitiba, Lapa, Piraquara, Quitandinha, Campina Grande do Sul, Agudos do Sul, Almirante Tamandaré, Araucária e Balsa Nova) têm o setor do turismo como uma política econômica municipal. Já 4 municípios (Adrianópolis, Campo Largo, Cerro Azul e Dr. Ulysses) concebem o turismo como uma Política do Turismo e 1 (São José dos Pinhais) insere o setor nas diretrizes prioritárias da macroproposta do plano diretor. As diretrizes contemplam o desenvolvimento e gerenciamento do turismo local e regional, com foco na promoção de mecanismos de identificação e estruturação de locais de interesse histórico, turístico, e também o incentivo de parcerias com a iniciativa privada para garantir o atendimento das aspirações da comunidade, promovendo a integração sociocultural com a vizinhança. Já no plano do município de Quatro Barras a política de turismo não foi abordada de forma específica, com o turismo inserido no eixo de geração de emprego e oportunidades de trabalho. Outra seção do plano insere-o como atividade econômica. Observa-se que este município tem o turismo como fator econômico e social. E, por último, 1 plano (Colombo) trata do turismo dentro da política ambiental.

Apesar de haver alguns objetivos e diretrizes distintos nos planos diretores, a maioria tem como objetivo principal aproveitar e desenvolver o potencial turístico natural e cultural, de forma sustentável. Assim, as diretrizes nos planos diretores contemplam que o turismo deverá se desenvolver na área rural e áreas de proteção ambiental, preservando o patrimônio cultural e natural. Observa-se que os municí- 
pios pesquisados possuem vastas áreas rurais, para as quais a proposta no Plano de Desenvolvimento da RMC Integrado é o desenvolvimento do turismo rural. Dentre os 17 planos analisados apenas 4 citam o plano municipal de turismo como instrumento técnico para gestão, coordenação e condução das decisões.

Ainda, em se tratando dos planos diretores, de acordo com os incisos da Lei n.o 10.257, os municípios da RMC inserem-se nos critérios estabelecidos: muitos têm mais de 20.000 habitantes, são integrantes de uma região metropolitana e aglomerado urbano e de áreas de especial interesse turístico, e ainda, estão inseridos na área de influência de empreendimentos ou atividades com significativo impacto ambiental regional ou nacional.

Percebeu-se também que as diretrizes, objetivos, estratégias dos planos e políticas para o setor foram citados nos planos de acordo com a empresa contratada para execução do plano e sua equipe técnica, ou seja, na elaboração dos planos diretores aparecem interesses distintos.

Neste sentido, Pilotto et al (2009, p. 342) afirmam que "O planejamento é uma construção social [..], expressa correlações de força e interesses específicos de classes ou grupos sociais".

No âmbito deste trabalho, contudo, essa questão se apresentou apenas como uma observação pois não se analisou a participação dos grupos na proposta da elaboração de um plano diretor, técnicos, políticos, organizações da sociedade civil e toda e qualquer pessoa, embora estes sejam os protagonistas do processo.

\subsection{0 cenário dos instrumentos de planejamento nas gestões muni- cipais de turismo}

De acordo com Hall (2001), a participação das organizações no planejamento e o preparo das comunidades são importantes, porém devem ser produtos dos arranjos institucionais, dos indivíduos, das estruturas de poder, dos interesses e valores que afetam o processo de tomada de decisão em diferentes escalas.

Neste contexto, algumas questões foram apresentadas aos gestores municipais do turismo, conforme os objetivos da pesquisa. Das respostas obtidas, elaborou-se o quadro abaixo: 
QUADRO 1: ORGANIZAÇÃO DO TURISMO NO MUNICÍPIO

\begin{tabular}{|l|c|c|}
\hline TIPO & FREQ & ANO DE CRIAÇÃO \\
\hline Secretaria de Turismo & 2 & 2009 \\
\hline Departamento de Turismo & 6 & 2008,2009 \\
\hline $\begin{array}{l}\text { Secretaria Indústria, Comércio, Turismo e Meio } \\
\text { Ambiente }\end{array}$ & 3 & 2009 \\
\hline Outra & 5 & $2005 ; 2009$ \\
\hline Não possui nenhuma & 4 & - \\
\hline
\end{tabular}

FONTE: A autora (2012).

Identifica-se que 4 municípios não possuem nenhum tipo de secretaria de turismo, em 5 deles o setor de turismo é representado por outros setores, enquanto que em 3 o setor está inserido na Secretaria de Indústria, Comércio, Turismo e Meio Ambiente, em 6 existem Departamentos de Turismo e 2 possuem Secretarias de Turismo.

Os municípios que não têm nenhum tipo de secretaria ou departamento são aqueles que não estão desenvolvendo nenhum tipo de atividade de turismo e também são os que têm mais problemas sociais, econômicos e ambientais. Conforme os entrevistados, os municípios não participam do processo de planejamento, pois têm outras prioridades, e também porque o município não tem nada a oferecer nesse campo.

Na visita às prefeituras verificou-se que vários setores fazem parte de uma única secretaria e que a maioria das prefeituras não tem espaço físico definido para o funcionamento da secretaria ou departamento da área de turismo.

No Quadro 1 verifica-se também que as secretarias e os departamentos foram todos criados a partir de 2005. Embora os dados do Quadro 1 apontem isso, pelo menos 10 prefeituras já em 1999 estavam elaborando os circuitos e participavam do Programa Nacional de Municipalização do Turismo (PNMT), cujo critério para inserção era possuir órgãos oficiais de turismo, de acordo com o representante da Secretaria Estadual de Turismo. Desse modo, algumas secretarias ou departamentos foram criados antes de 2005, conforme a pesquisa documental e de observação. Esta resposta com viés divergente se deu por conta da descontinuidade na administração das prefeituras municipais, cujas secretarias de turismo ou departamentos foram extintos. Exemplo disso são Campo Largo, Agudos do Sul, Almirante Tamandaré, e outros. Ademais, dependendo da gestão algumas secretarias foram integradas a outras.

De uma forma geral, quando se trata de planejamento integrado na RMC, o processo de gestão metropolitana atualmente apresenta-se desgastado e ineficaz, o que pode ser atribuído 
[..] às questões político-partidárias envolvidas, à descontinuidade de governos, à falta de integração e articulação intersetorial e interinstitucional dos entes responsáveis pela execução das políticas municipais e estaduais, às desigualdades entre os municípios para a participação nos processos de discussão e gestão, à hegemonia apresentada pelo município de Curitiba e à inexistência de instrumentos para integração das organizações envolvidas com o planejamento. (GORSDORF, 2009, p. 367)

Dessa maneira, quando se observa a falta de continuidade dos governos, de integração e articulação intersetorial e municipal, a tendência é que planos, programas e projetos não perdurem por muito tempo. Em função disso, o setor de turismo, cujas ações se dão em médio e longo prazo, não se materializa, havendo um retrocesso no processo de planejamento na Região.

Constatou-se que naqueles municípios que mantiveram funcionários desde o início do processo da organização e do planejamento da atividade turística, ocorreu uma evolução do turismo, com a produção e comercialização de circuitos turísticos.

Queiroz (2009) argumenta que esses servidores são imprescindíveis para o funcionamento do Estado Democrático de Direito, por proporcionarem as condições para as decisões políticas dos que governam e fundamentalmente no sentido de trabaIhar pelo interesse coletivo. Porém, não é o que acontece muitas vezes no Brasil, pois decisões são tomadas não raro por agentes políticos, ou seja, no exercício de cargos comissionados, que não dão continuidade ao planejamento e ordenamento territorial. Nesse aspecto, a participação de gestores comprometidos e qualificados para o planejamento se torna imprescindível.

Nesse sentido, foi perguntado para os entrevistados sobre as ferramentas de planejamento que são utilizadas pelos municípios da RMC para execução das políticas públicas do turismo. O resultado é o que segue:

QUADRO 2: GESTÃO MUNICIPAL DO TURISMO NA RMC

\begin{tabular}{|l|c|c|c|}
\hline INSTRUMENTOS DE ORGANIZAÇÃO DO TURISMO & SIM & NÃO & SEM RESPOSTA \\
\hline O município tem Plano Diretor & 20 & 0 & \\
\hline No plano está inserido o setor de turismo & 15 & 5 & \\
\hline O turismo participou da execução do Plano Diretor & 14 & 6 & \\
\hline Possui COMTUR & 11 & 9 & \\
\hline Possui FUMTUR & 6 & 13 & 1 \\
\hline O FUMTUR é legitimado & 4 & 1 & 15 \\
\hline
\end{tabular}

FONTE: A autora (2012). 
Observa-se que 20 municípios visitados possuem planos diretores, e segundo os entrevistados, 15 deles contemplam o setor de turismo. Comparando esse quadro com as entrevistas dos gestores, percebe-se que 5 gestores não tiveram acesso ao plano diretor dos seus municípios, pois não sabiam da inserção do turismo no plano diretor.

O plano diretor e o planejamento estrátegico municipal, com respaldo da Constituição Federal, do Estatuto da Cidade e da Lei de Responsabilidade Fiscal, são instrumentos técnicos fundamentais para a gestão pública municipal (REZENDE e ULTRAMARI, 2007). No entanto, este instrumento ainda não é utilizado por todos os gestores do turismo da RMC como ferramenta de apoio ao planejamento territorial do turismo.

Foi também identificado quando os planos foram elaborados e/ou aprovados para verificar se estavam de acordo com o Estatuto da Cidade e se coincidem com o planejamento territorial do turismo na RMC, conforme Gráfico 1:

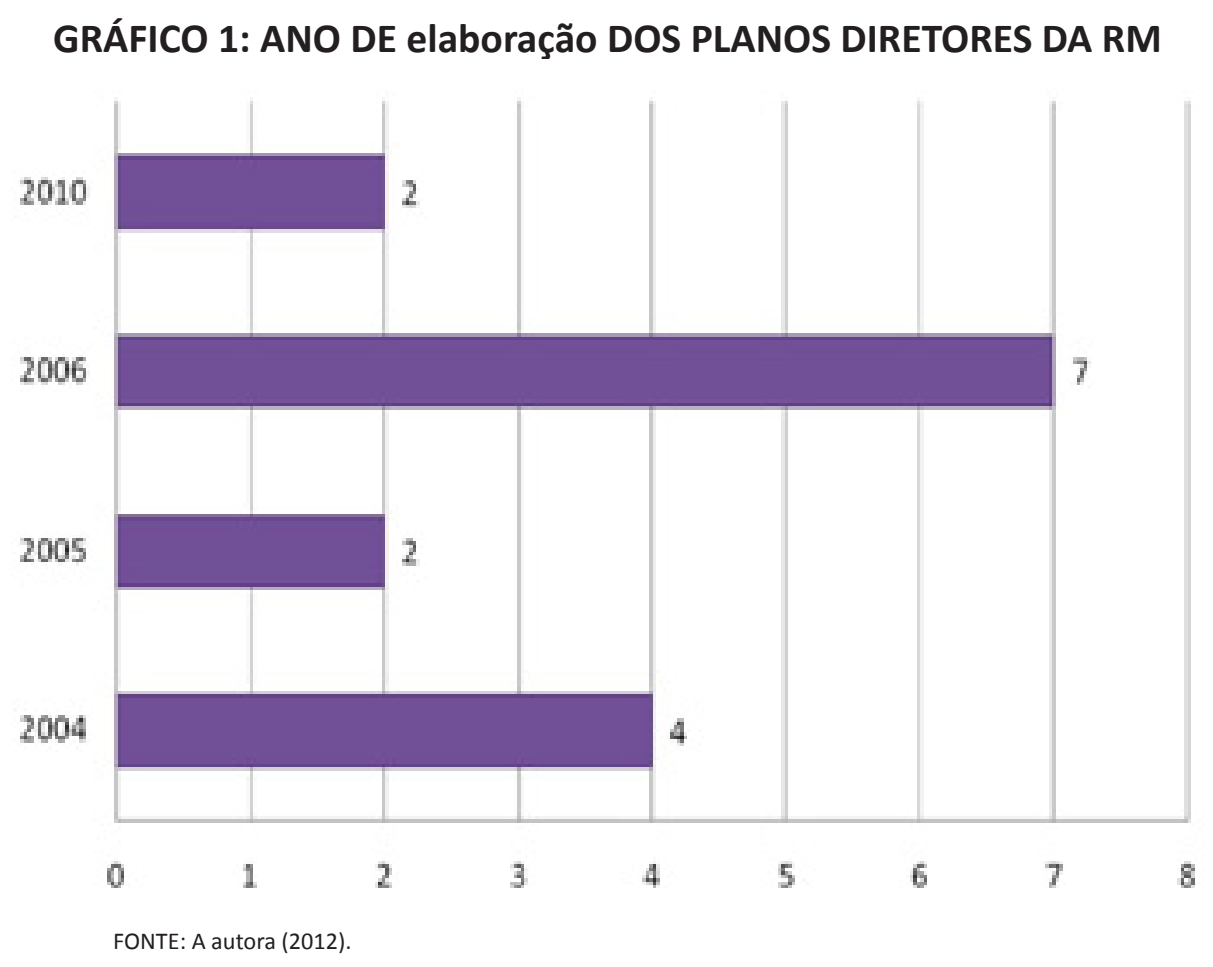

Verifica-se no gráfico acima que foram aprovados 7 planos diretores em 2006, 4 em 2004, 2 em 2005 e 2 em 2010. Coincidem, portanto, com a exigência da legisla- 
ção estadual de elaboração dos planos diretores. ${ }^{2}$

Comparando o Quadro 1 com o Gráfico 1, identifica-se que a organização do turismo na RMC coincide com a elaboração dos planos diretores, embora estes não tenham servido de base para o planejamento do turismo, conforme verificou-se das entrevistas com os gestores municipais do setor.

Quando se trata do Conselho Municipal de Turismo (COMTUR), instrumento de formulação, promoção e execução da política municipal de turismo, ele está presente em 11 dos 20 municípios visitados. Quando perguntado se os conselhos estavam ativos, obteve-se o seguinte resultado: 6 estavam desativados, 1 não respondeu e 4 não tinham conselho. Ainda, questionado como eram formados, foi respondido que pelo setor público e privado. Em relação ao fundo municipal de turismo, 6 o possuem, sendo 4 destes legitimados.

Como se observa, dos municípios pesquisados, poucos têm fundo municipal de turismo. $O$ "fundo é uma ferramenta essencial na captação de recursos e auxilia na concretização de projetos", que visam ao desenvolvimento de forma efetiva (SETU, 2005, p. 34).

Nota-se que a institucionalização do turismo nos municípios da RMC ainda não é prioridade, o que pode ser concluído a partir das ações de planejamento, verificadas com os gestores municipais.

Se o turismo não se encontra inserido em nenhum dos planos de desenvolvimento urbano e regional, no plano de desenvolvimento do turismo ou no código de obras, deve-se buscar qualquer um desses instrumentos legais e de planejamento. Nesse sentido, a legislação federal determina que a atividade turística deve estar inserida na legislação municipal de acordo com o perfil do município (YAGIZI,1999).

\section{Considerações finais}

O planejamento do turismo constitui uma tarefa complexa uma vez que envolve diversos fatores, tais como a ocupação terrritorial, a política econômica, social, ambiental e cultural de um local.

A situação que se observa na RMC é que o planejamento do turismo dos municípios transita no plano diretor nas áreas econômica e ambiental. A maioria dos municípios não possui uma política municipal de turismo, descaso do ponto de vista

2 Decreto no 2.581, de 17/02/2004, posteriormente regulamentado pela Lei Estadual de Desenvolvimento Urbano no 15.299, de 26 de julho de 2006, que exigiram a elaboração de Planos Diretores nos 399 municípios do Estado do Paraná, assim como os resultados desse processo desde 2003 até 2006 (PEREIRA JR, 2007, p. 2). 
"ético e político" cuja tendência é o enfraquecimento da atividade.

As temáticas do turismo e do meio ambiente são recentes na pauta do planejamento urbano, com exceção dos municípios do Rio de Janeiro e Manaus que já fazem parte do processo há décadas. Diante disto, o planejamento urbano deve almejar lidar de forma "equilibrada e equânime com as dimensões ambiental, econômica, social, infraestrutural, gerencial e territorial que abrangem a vida urbana" (DUARTE, 2007, p. 68-70).

Em relação aos instrumentos diretamente relacionados com o turismo, conselho, fundo e órgão municipal, desde a elaboração do primeiro projeto de turismo na Região, a recomendação da Secretaria Estadual do Turismo do Paraná e do Ministério do Turismo é para que se utilizem tais instrumentos para o processo de organização e planejamento do turismo, constituído pelo setor público, privado e sociedade civil. Identificou-se, porém, que muitos conselhos e fundos só existem no papel, visto que estão desativados. Desse modo, os municípios ficam praticamente sem condições de buscar recursos para os projetos no âmbito público, uma vez que os conselhos são utlizados como critério para liberação de recursos.

Diante desta situação, o Estado precisa criar estratégias de valorização das ferramentas de planejamento e ordenamento territorial do turismo com vistas a identificar se o turismo é um vetor de desenvolvimento para escala local e regional. Além disso, os gestores municipais devem ser conscientizados, na mudança de gestão, para a necessidade de continuação no processo de planejamento, visando ao desenvolvimento turístico.

Ainda que a pesquisa tenha tido diversos limites, tendo pretendido apenas lançar questões a respeito do Plano Diretor como instrumento de planejamento para o desenvolvimento do turismo, identificou-se que as questões físico-territoriais, econômicas, financeiras, políticas, sociais, ambientais, são desafiadoras e prioritárias para os gestores municipais da RMC, frente às questões turísticas. Principalmente porque este setor faz parte de uma política de desenvolvimento econômico da RMC por meio da Política Nacional do Turismo e seu ordenamento deve estar pautado no planejamento municipal como um setor distinto, mas integrado aos demais setores.

Margarete Araujo Teles, Geógrafa e Bacharel em Turismo, Professora Adjunta do Curso de Turismo da Universidade Federal do Paraná, Doutora em Geografia, Curitiba, Paraná, Brasil 


\section{Referências}

BENI, M. Análise estrutural do turismo. 9.ed. São Paulo: Senac, 2003.

BRASIL. Constituição da República Federativa do Brasil, de 05 de outubro de 1988. DOU, Brasília, DF, 05 out. 1988. Disponível em: <http://www.planalto.gov.br/ civil_03/constituicao/constitui\%C3\%A7ao.htm>. Acesso em: 14 abr. 2011.

. Ministério do Turismo. Projeto Inventário da Oferta Turística/Programa de

Regionalização do Turismo: roteiros do Brasil. Brasília, 2006.

. Ministério do Turismo. Plano Nacional do Turismo 2007/2010: uma viagem de inclusão. Brasília, 2007.

. Estatuto da Cidade. Brasília: Senado Federal. Secretaria, Subsecretaria de Edições Técnicas, 2008. 102p.

COORDENADORIA DA REGIÃO METROPOLITANA DE CURITIBA - COMEC. Plano de Desenvolvimento Integrado 2006. Curitiba, 2006.

COOPER, C.; FLETCHER, J.; WANHILL, S. Turismo: princípios e práticas. 3.ed. Porto Alegre: Bookmann, 2007.

CRUZ. R. C. Planejamento governamental do turismo: convergências e contradições na produção do espaço. In: LEMOS, A. I. G.; ARROYO, M.; SILVEIRA, M. L. América Latina: cidade, campo e turismo. Buenos Aires: CLACSO, São Paulo: Universidade de São Paulo, 2006.

DESCHAMPS, M. V.; CINTRA, A. P. Movimento pendular para trabalho na Região Metropolitana de Curitiba: uma análise das características de quem sai e quem fica. In: MOURA, R.; FIRKOWSKI, O. L. C. (Orgs.). Dinâmicas intrametropolitanas e produção do espaço da Região Metropolitana de Curitiba. Rio de Janeiro: Observatório das Metrópoles: Observatório de Políticas Públicas Paraná; Curitiba: Letra Capital, 2009. p.233-251.

DUARTE, F. Planejamento Urbano. 20 ed. Curitiba: IBPEX, 2007.

GORSDORF, L. F. A dimensão nos planos diretores municipais da Região Metropolitana de Curitiba. In: MOURA, R.; FIRKOWSKI, O. L. C. (Orgs.). Dinâmicas intrametropolitanas e produção do espaço da Região Metropolitana de Curitiba. Rio de Janeiro: Observatório das Metrópoles: Observatório de Políticas Públicas Paraná; Curitiba: Letra Capital, 2009. p. 363.

INSITUTO PARANAENSE DE DESENVOLVIMENTO ECONÔMICO E SOCIAL - IPARDES. Perfil da Região Metropolitana de Curitiba: Mesorregião Geográfica Metropolitana de Curitiba. Curitiba: IPARDES, 2011. 
- Leituras regionais: Mesorregião Geográfica Metropolitana de Curitiba. Curitiba: IPARDES, 2004. 219 p.

HALL, C. R. Planejamento turístico: políticas, processos e relacionamentos. São Paulo: Contexto, 2001.

MOURA, R.; FIRKOWSKI, O. L. C. (Orgs.). Dinâmicas intrametropolitanas e produção do espaço da Região Metropolitana de Curitiba. Rio de Janeiro: Observatório das Metrópoles: Observatório de Políticas Públicas Paraná; Curitiba: Letra Capital, 2009.

PEREIRA JR., G. Elaboração de planos diretores no estado: uma discussão sobre os resultados e as continuidades. Dissertação (Mestrado) - Pontifícia Universidade Calica do Paraná - PUCPR, Curitiba, 2007.

PILOTTO, J. A. S; FARIA, J. R. V.; ARAUJO, R. R. DE, Interesses em disputa em planos diretores da RMC. In: MOURA, R.; FIRKOWSKI, O. L. C. (Orgs.). Dinâmicas intrametropolitanas e produção do espaço da Região Metropolitana de Curitiba. Rio de Janeiro: Observatório das Metrópoles: Observatório de Políticas Públicas Paraná; Curitiba: Letra Capital, 2009. p. 342.

PREFEITURA MUNICIPAL DE ADRIANÓPOLIS. Plano Diretor - minuta (SEDU), 2010. PREFEITURA MUNICIPAL AGUDOS DO SUL. Lei do Plano Diretor Municipal de Agudos do Sul $n .{ }^{\circ} 368 / 2006$.

PREFEITURA MUNICIPAL DE ALMIRANTE TAMANDARÉ. Lei Complementar $\mathbf{n}$. $^{\circ}$ 1/2006. PREFEITURA MUNICIPAL DE ARAUCÁRIA. Plano Diretor Participativo de Araucária. Araucária, 2006. v.2. Propostas

PREFEITURA MUNICIPAL DE BALSA NOVA. Plano Diretor - Lei n. ${ }^{\circ}$ 483/2007. PREFEITURA MUNICIPAL DE CAMPINA GRANDE DO SUL. Plano Diretor - Lei n. ${ }^{\circ}$ 49/2004. Regulamentada pela Lei n. ${ }^{\circ} 31 / 2009$.

PREFEITURA MUNICIPAL DE CAMPO LARGO. Plano Diretor - Lei n. ${ }^{\circ}$ 1812/2005.

PREFEITURA MUNICIPAL DE CAMPO MAGRO. Plano Diretor de Desenvolvimento Integrado de Campo Magro (2004-2005). v.1.

PREFEITURA DE MUNICIPAL DE CERRO AZUL. Plano Diretor. 2010.

PREFEITURA MUNICIPAL DE COLOMBO. Plano Diretor - Lei Complementar n. ${ }^{\circ} 875 / 2004$.

PREFEITURA MUNICIPAL DE CONTENDA. Plano Diretor Lei Complementar n. ${ }^{\circ} 002 / 2009$. 
PREFEITURA MUNICIPAL DE CURITIBA. Lei Ordinária n. ${ }^{\circ}$ 11266/2004.

PREFEITURA MUNICIPAL DE FAZENDO RIO GRANDE. Lei Complementar n. ${ }^{\circ}$ 4/2006. PREFEITURA MUNICIPAL DA LAPA. Plano Diretor do Município da Lapa, 2003.

PREFEITURA MUNICIPAL DE PINHAIS. Plano Diretor Preliminar. Disponível em: $<$ http://www. pinhais.pr.gov.br/aprefeitura/secretariaseorgaos/desenvolvimentosustentavel/FreeComponent64content414.shtml>. Acesso em: 15 abr. 2011.

PREFEITURA MUNICIPAL DE PIRAQUARA. Plano Diretor - Lei n. ${ }^{\circ}$ 854/2006.

PREFEITURA MUNICIPAL DE QUITANDINHA. Plano Diretor Municipal de Uso e Ocupação do Solo de Quitandinha. Quitandinha, 2007. Produto 2 - Avaliação Temática Integrada.

PREFEITURA MUNICIPAL DE QUATRO BARRAS. Projeto de Lei Complementar n. ${ }^{\circ} 001 / 2006$.

PREFEITURA MUNICIPAL DE SÃO JOSÉ DOS PINHAIS. Plano Diretor - Lei Complementar $n .^{\circ}$ 09/2004.

PREFEITURA MUNICIPAL DE TIJUCAS DO SUL. Minuta Plano Diretor. SEDU, 2010. QUEIROZ, R. B. Formação e gestão de políticas públicas. 2. ed. Curitiba: Ibpex, 2009. RIBEIRO, M.R. Planos diretores, perspectiva legal e organização do território para o turismo. Turismo \& Sociedade. Curitiba, v. 6, n. 4, p. 911-915, outubro de 2013. REZENDE, D. A; ULTRAMARI, C. Plano diretor e planejamento estratégico municipal: introdução teórico-conceitual. Rio de Janeiro: RAP. v. 41(2) p. 255-271. 2007.

SECRETARIA ESTADUAL DE TURISMO DO ESTADO DO PARANÁ (SETU). Manual de orientação para gestão municipal de turismo. Curitiba, 2005.

SILVEIRA, M. A. T. DA. Turismo, políticas de ordenamento territorial: um foco no estado do Paraná no contexto regional. Tese (Doutoramento) - USP, São Paulo, 2002.

TELES, M. A. Turismo, ordenamento territorial e desenvolvimento na região metropolitana de Curitiba - PR. 278 p. (Doutoramento) - Setor de Ciências da Terra, UFPR, Curitiba, 2011.

YÁZIGI, E. Saudades do futuro: por uma teoria do planejamento do turismo. São Paulo: Plêiade, 2009. Turismo: uma esperança incondicional. 2. ed. São Paulo: Global, 1999. 